\title{
SIMULASI KERUNTUHAN BENDUNGAN BILI-BILI KABUPATEN GOWA PROVINSI SULAWESI SELATAN
}

\author{
Rustan $^{1 *}$, Irpan Chumaedi ${ }^{2}$, Linda Handayani $^{1}$ \\ ${ }^{1}$ Prodi Fisika, Fakultas Sains dan Teknologi, Universitas Jambi, Mendalo Indah, Jambi, 36361, Indonesia \\ ${ }^{2}$ Prodi Teknik Sipil, Universitas Jenderal Achmad Yani, Indonesia \\ *e-mail: rustan.rustan@unja.ac.id
}

\begin{abstract}
ABSTRAK
Cuaca ekstrim yang terjadi pada tanggal 22-24 Januari 2019 di wilayah kota Makassar dan sekitarnya mengakibatkan banjir besar di wilayah hilir dari bendungan Bili-Bili yang meliputi 5 kabupaten dan kota yaitu Kabupaten Gowa, Kota Makassar, Kabupaten Jeneponto, Kabupaten Maros, dan Kabupaten Selayar. Sebanyak 6757 orang mengungsi dan puluhan hektar sawah dan perumahan yang terendam. Sebagai bentuk evaluasi dalam rangka upaya mitigasi bencana apabila kejadian serupa atau yang lebih besar terjadi di masa yang akan datang, maka sangat penting dilakukan simulasi banjir untuk memetakan daerah mana saja yang akan terdampak genangan banjir apabila bendungan Bili-Bili mengalami keruntuhan. Perangkat lunak yang digunakan untuk mensimulasikan banjir dalam penelitian ini adalah HEC-RAS 2D. Objek penelitian difokuskan di kota Makassar yang merupakan pusat kota yang padat penduduk dan objek vital lainnya. Parameter yang di analisis adalah distribusi luas genangan banjir dan kedalaman genangan banjir. Hasil simulasi yang sudah dikalibrasi akan dijadikan referensi untuk rencana mitigasi bencana.
\end{abstract}

Kata Kunci: Keruntuhan Bendungan; HEC-RAS 2D; Mitigasi Bencana, Bendungan Bili-Bili.

\begin{abstract}
[Title: Simulation of Bili-Bili Dam Failures in Gowa Regency, South Sulawesi Province] The extreme weather that occurred on January 22-24, 2019 in the Makassar city and surrounding areas caused massive flooding in the downstream area of the Bili-Bili DAM which covered 5 districts and cities, namely Gowa Regency, Makassar City, Jeneponto Regency, Maros Regency, and Selayar Regency. There 6757 people were displaced and tens of hectares of rice fields and housing were inundated. As a form of evaluation in the context of disaster mitigation efforts if similar or larger events occur in the future, it is very important to do a floods simulation to mapping which areas will be affected by flood inundation if the Bili-Bili DAM collapses. The software used to simulate flooding in this study is HEC-RAS 2D. The object of research is focused in the city of Makassar which is a densely populated city center and other vital objects. The parameters analyzed are the distribution offlood inundation area and the depth offlood inundation. Simulation results that have been calibrated will be used as a reference for disaster mitigation planning.
\end{abstract}

Keywords: Dam Failure; HEC-RAS 2D; Hazard Mitigation, Bili-Bili Dam.

\section{PENDAHULUAN}

Bendungan Bili-Bili merupakan bendungan terbesar yang ada di Provinsi Sulawesi Selatan, yang terletak $\pm 30 \mathrm{~km}$ di sebelah timur Kota Makassar tepatnya di Dusun Bili-Bili, Desa Romangloe, Kecamatan Parangloe, Kabupaten Gowa. Bendungan Bili-Bili merupakan bendungan multifungsi, antara lain sebagai pengendali banjir (reduksi debit 2200 $\mathrm{m}^{3} /$ detik menjadi $1200 \mathrm{~m}^{3} /$ detik), penyediaan sumber air baku sebesar 3300 liter/detik, pelayanan air irigasi dengan luas potensial 23690 hektar, Pembangkit Listrik Tenaga Air (PLTA) dengan kapasitas terpasang 20.1 MW, pariwisata/olahraga air, dan perikanan darat (PDSA Sulsel, 2010).

Terjadinya cuaca ekstrim di akhir bulan Januari 2019 di Sulawesi Selatan menyebabkan kenaikan ketinggian dan volume air bendungan BiliBili. Tercatat pada tanggal 23 Januari 2019 elevasi mencapai $+100,74 \mathrm{~m}$ jauh melampaui di atas elevasi normal $+99,50 \mathrm{~m}$. Sesuai prosedur standar jika elevasi air melewati batas normal, maka pintu air bendungan terpaksa harus dibuka untuk mencegah terjadinya keruntuhan bendungan (BPSDM, 2017). 
Keruntuhan bendungan dapat terjadi disebabkan oleh overtopping maupun karena piping. Overtopping adalah elevasi muka air di hulu bendungan melebihi elevasi mercu sehingga air melimpas melewati mercu bendungan sedangkan piping merupakan kondisi air sungai yang terbendung oleh bendungan dapat mengalir ke dalam tanah menyusur dasar dan dinding bendungan alam (Brunner, 2014).
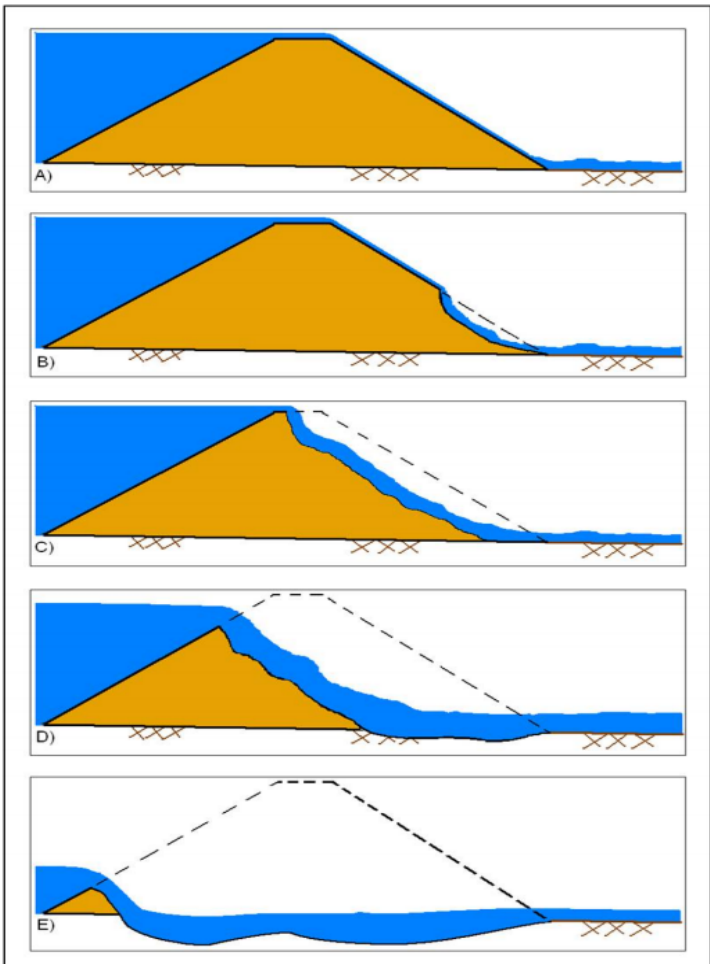

Gambar 1. Keruntuhan bendungan karena overtopping

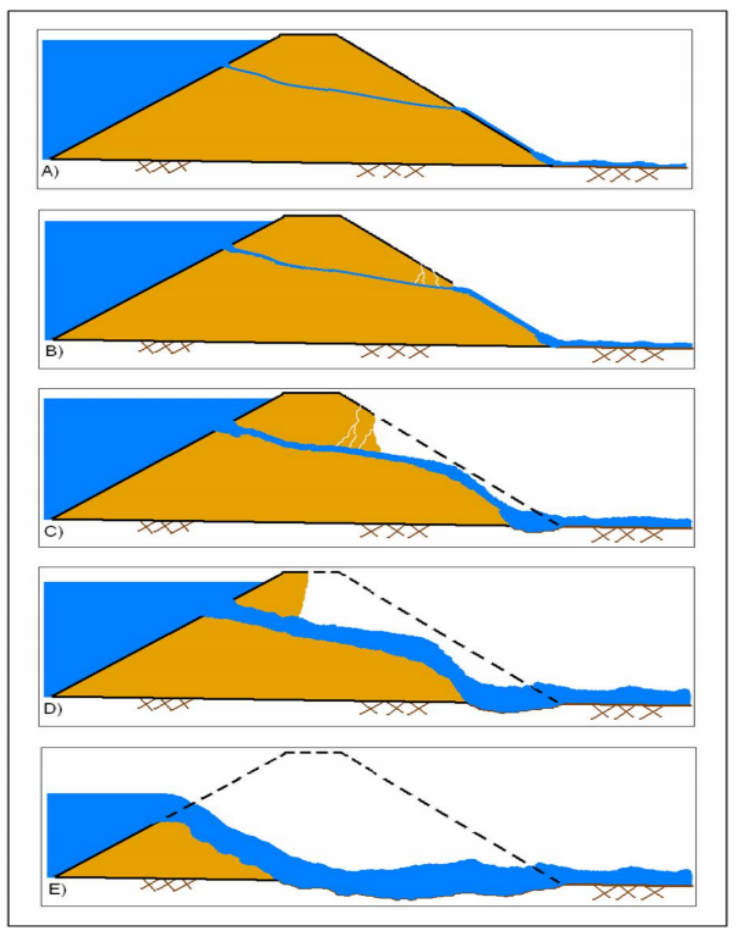

Gambar 2. Keruntuhan bendungan karena piping
Bencana banjir besar dapat terjadi apabila bendungan mengalami keruntuhan. Air yang tertampung dalam bendungan akan mengalir menuju hilir dengan debit yang sangat besar dan kecepatan yang tinggi. Dan apabila kapasistas sungai tidak mampu menampung aliran air, maka air akan meluap keluar sungai dan menggenangi daerah hilir yang umumnya adalah pemukiman penduduk. Untuk prediksi banjir di hilir akibat keruntuhan bendungan, biasanya diasumsikan bahwa bendungan runtuh total dan mendadak (Rachmadan, 2013). Pemodelan aliran air akibat keruntuhan bendungan dapat dilakukan dengan bantuan software seperti DAMBRK, SMPDBK, FLDWAV, dan HEC-RAS (Xiong, 2011). Model HEC-RAS 2D sangat cocok dan mudah digunakan untuk menentukan kedalaman air, luas genangan, kecepatan aliran, dan profil muka air dalam bentuk dua dimensi (Goodell dan Warren, C, 2006). Dengan analisis parameter-parameter tersebut akan dapat diketahui risiko bencana pada wilayah yang berpotensi terdampak banjir di suatu wilayah.

Penelitian ini bertujuan untuk menganalisis keruntuhan bendungan Bili-Bili untuk mensimulasikan distribusi genangan dan kedalaman genangan banjir menggunakan program HEC-RAS 2D. Kejadian banjir pada tanggal 23 Januari 2019 akan digunakan sebagai validasi dari hasil simulasi ini.

\section{METODE}

\section{Gambaran Lokasi Penelitian}

Bendungan Bili-Bili terletak $30 \mathrm{~km}$ di timur kota Makassar dan terletak pada ketinggian $100 \mathrm{~m}$ diatas permukaan laut (dpl). Secara geografis, bendungan Bili-Bili memiliki koordinat 5 16'46" LS dan $119^{\circ} 35^{\prime} 08^{\prime \prime}$ LU.

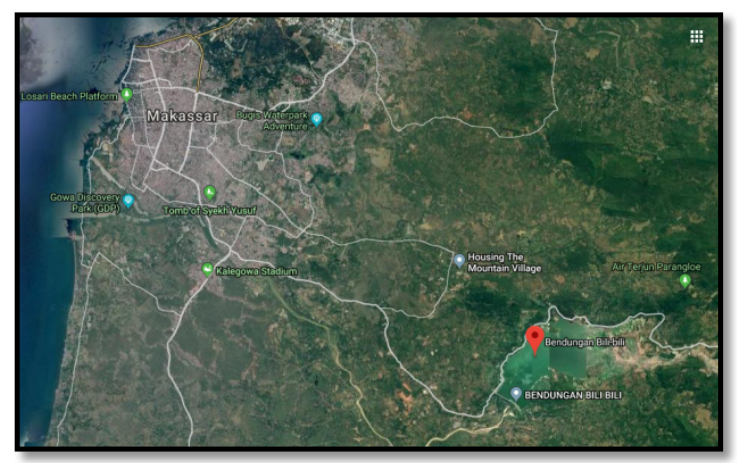

Gambar 3. Bendungan Bili-Bili berjarak $30 \mathrm{~km}$ di sebelah timur kota Makassar

\section{Pengumpulan Data}

Data yang digunakan adalah data sekunder. Data yang dibutuhkan pada penelitian ini antara lain:

a) Informasi Bendungan Bili-Bili berupa data teknis bendungan, pola operasi pintu, inflow dan outflow bendungan dengan interval 10 menit 
b) Data topografi DEM Nasional dengan resolusi 8.4 $\times 8.4$ meter

c) Peta Rupa Bumi Indonesia skala 1:50000

\section{Langkah Pengerjaan Simulasi dengan HEC-RAS}

Untuk membuat model hidraulika dengan HECRAS dapat dilakukan dengan lima langkah sebagai berikut:

a) Membuat project

Untuk membuat simulasi, dimulai dengan membuat proyek baru (new project) dengan memberi nama dan menyimpannya.

b) Memasukkan data geometri

Untuk membuat geometri, klik menu Edit pada tampilan awal HEC-RAS, kemudian klik Enter Geometric Data.

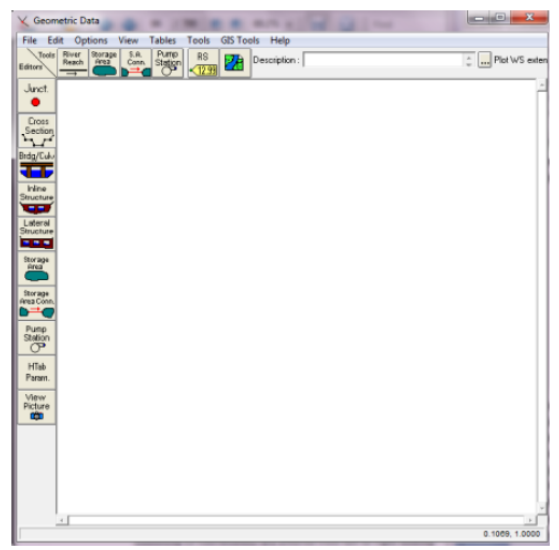

Gambar 4. Tampilan Geometri Data HEC-RAS

c) Memasukkan hidraulika sungai

Hidraulika sungai meliputi jumlah profil, data aliran, lokasi perubahan aliran, kondisi batas, dan kondisi awal.

d) Melakukan perhitungan hidraulika

Perhitungan hidraulika aliran setelah syarat awal dan syarat batas ditentukan dapat ditentukan melalui menu Run pada HEC-RAS.

e) Menampilkan hasil perhitungan

Hasil perhitungan pada HEC-RAS ditampilkan dalam bentuk tabel dan grafik. Pada setiap tampilan tersedia menu Option untuk memilih variabel dan parameter.

\section{Validasi Hasil Simulasi}

Pada tahap ini dilakukan validasi hasil simulasi HEC-RAS dengan kejadian banjir pada tanggal 23 Januari 2019, tepatnya di jembatan kembar Kabupaten Gowa.

\section{Generate Hasil Simulasi}

Tahap ini akan dilakukan apabila hasil model sudah mendekati kondisi kenyataan. Hasil yang ditampilkan antara lain luas genangan, kecepatan aliran, dan tinggi muka air.

Bagan alir penelitian dapat dilihat pada gambar berikut:

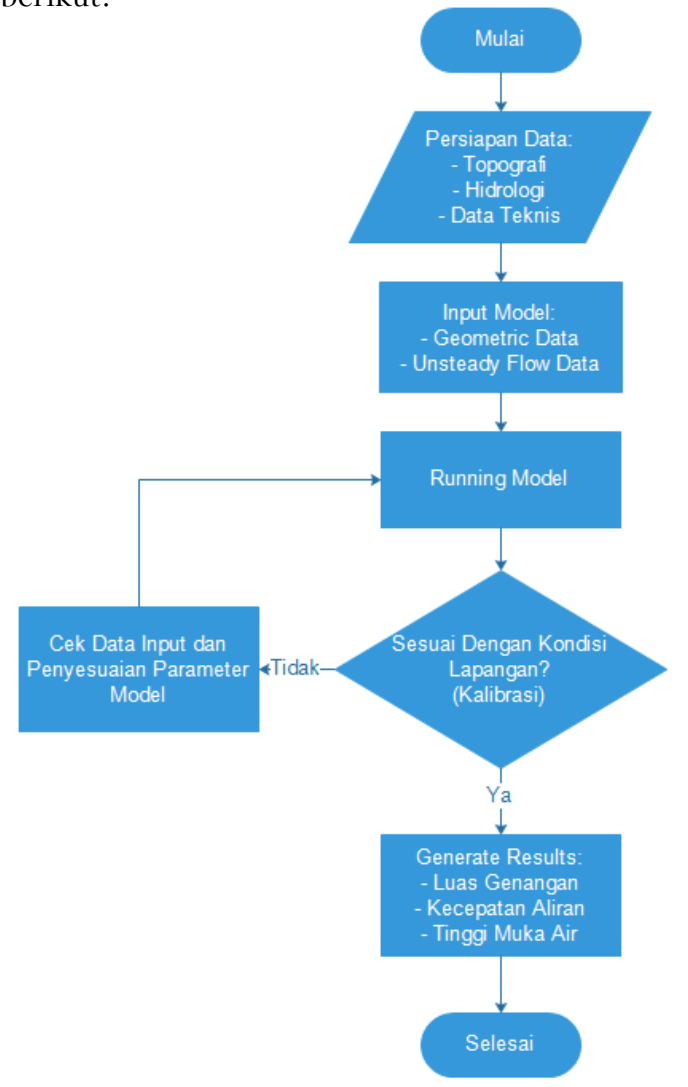

Gambar 5. Diagram Alir Penelitian

\section{HASIL DAN PEMBAHASAN}

\section{Peta Topografi dan Data Teknis Bendungan}

Peta topografi dibuat dengan menggunakan data DEM Nasional resolusi $8.4 \times 8.4$ meter. Peta topografi tersebut kemudian di-overlay-kan dengan Peta Administrasi Kecamatan yang berskala 1:50000. Hasil overlay peta dapat dilihat pada gambar berikut ini:

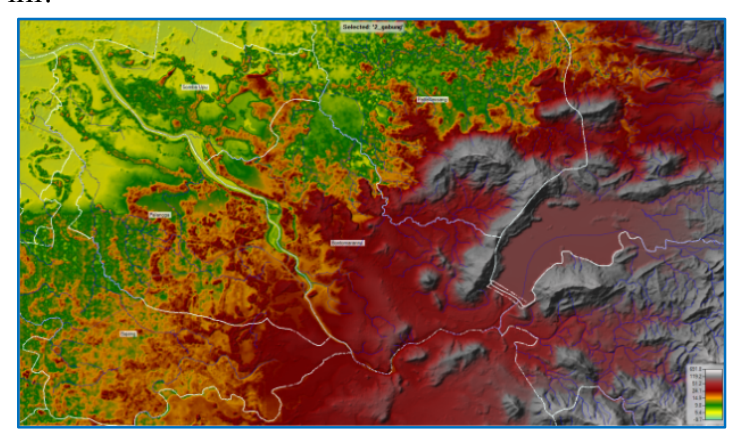

Gambar 6. Overlay Peta Topografi dengan Peta Administrasi Kecamatan 
Data teknis Bendungan Bili-Bili dapat dilihat pada tabel berikut:

\begin{tabular}{|c|c|c|}
\hline Nama Sungai & $:$ & Jeneberang \\
\hline Luas DAS & : & $784,01 \mathrm{~km}^{2}$ \\
\hline Luas genangan & : & 1650 hektar \\
\hline Banjir desain & $:$ & $1800 \mathrm{~m}^{3} /$ detik \\
\hline $\begin{array}{l}\text { Volume tampungan } \\
\text { maksimum }\end{array}$ & $:$ & 375 juta $\mathrm{m}^{3}$ \\
\hline $\begin{array}{l}\text { Volume tampungan } \\
\text { efektif }\end{array}$ & $:$ & 346 juta $\mathrm{m}^{3}$ \\
\hline Volume tampungan mati & $:$ & 29 juta $^{3}$ \\
\hline Elevasi muka air banjir & $:$ & $+103,0 \mathrm{~m}$ \\
\hline Elevasi muka air normal & : & $+99,50 \mathrm{~m}$ \\
\hline Elevasi muka air rendah & : & $+65,00 \mathrm{~m}$ \\
\hline Tipe Bendungan & $:$ & $\begin{array}{l}\text { Urugan Batu } \\
\text { dengan Inti }\end{array}$ \\
\hline $\begin{array}{l}\text { Tinggi bendungan dari } \\
\text { dasar sungai }\end{array}$ & $:$ & $56 \mathrm{~m}$ \\
\hline $\begin{array}{l}\text { Tinggi bendungan dari } \\
\text { pondasi }\end{array}$ & : & $73 \mathrm{~m}$ \\
\hline Elevasi puncak & : & $+106,00$ \\
\hline Panjang puncak & $:$ & $1808 \mathrm{~m}$ \\
\hline Lebar puncak & $:$ & $10 \mathrm{~m}$ \\
\hline Embankment & : & 5,29 juta $^{3}$ \\
\hline Spillway & $:$ & $\begin{array}{l}\text { Ogee dengan } \\
\text { pintu }\end{array}$ \\
\hline Debit banjir PMF & $:$ & $3800 \mathrm{~m}^{3} /$ detik \\
\hline Kapasitas Spillway & : & $2000 \mathrm{~m}^{3} /$ detik \\
\hline Panjang mercu pelimpah & $:$ & $70,00 \mathrm{~m}$ \\
\hline
\end{tabular}

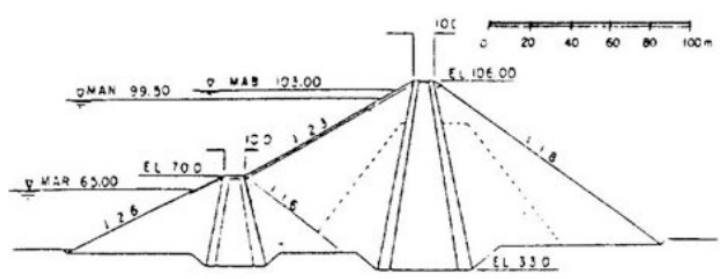

Gambar 7. Penampang melintang Bendungan Bili-Bili

\section{Skema Pemodelan}

Setelah peta hasil overlay diinput sebagai data geometri, langkah selanjutnya adalah menentukan inline structure bendungan, luas storage area bendungan, dan syarat batas aliran yang diinginkan. Pada saat menentukan inline structure, dilakukan pengaturan pintu Spillway, yaitu pintu terbuka ketika elevasi muka air di hulu berada pada $+99.43 \mathrm{~m}$. Debit inflow bendungan adalah $3464.98 \mathrm{~m}^{3} /$ detik dan debit inflow sungai Jenelata adalah $1212.743 \mathrm{~m}^{3} /$ detik. Hasil skema pemodelan dapat dilihat pada gambar berikut:

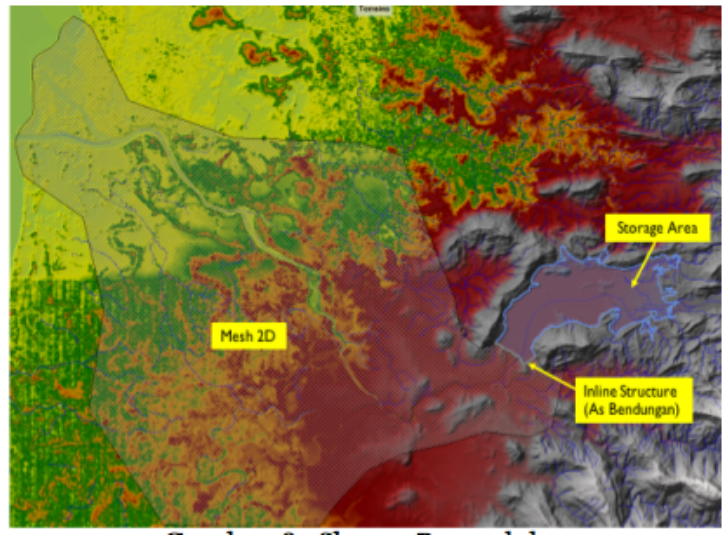

Gambar 8. Skema Pemodelan

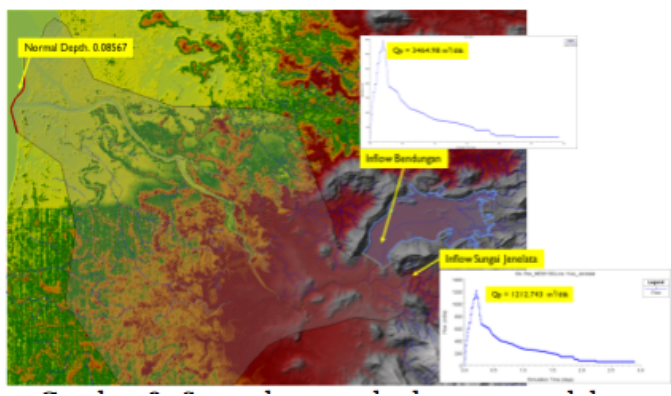

Gambar 9. Syarat batas pada skema pemodelan

\section{Hasil Simulasi}

Setelah semua input telah dimasukkan, langkah selanjutnya adalah running model.

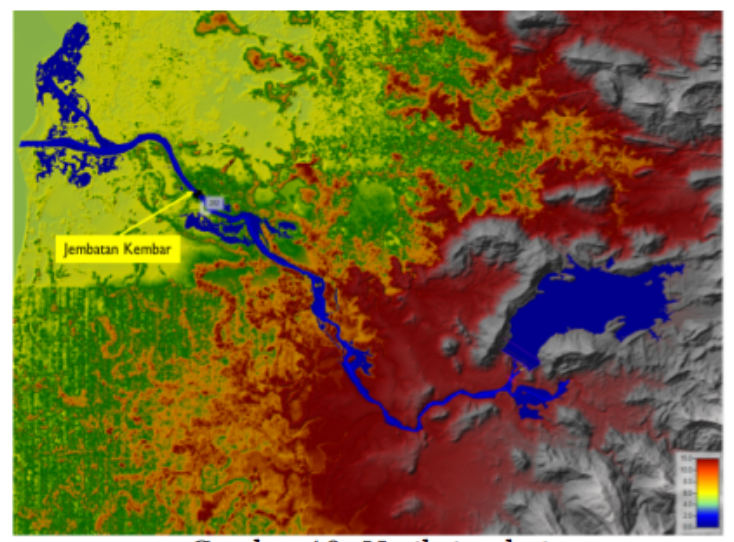

Gambar 10. Hasil simulasi

\section{Kalibrasi}

Untuk mengetahui model sudah berjalan dengan baik maka perlu dilakukan validasi dengan kondisi riil. Validasi dilakukan dengan tinggi muka air di sekitar Jembatan Kembar. Hasil validasi menunjukkan bahwa nilai ketinggian muka air hasil simulasi mendekati nilai ketinggian muka air kejadian sebenarnya yaitu setinggi 3 meter dari jembatan kembar. 


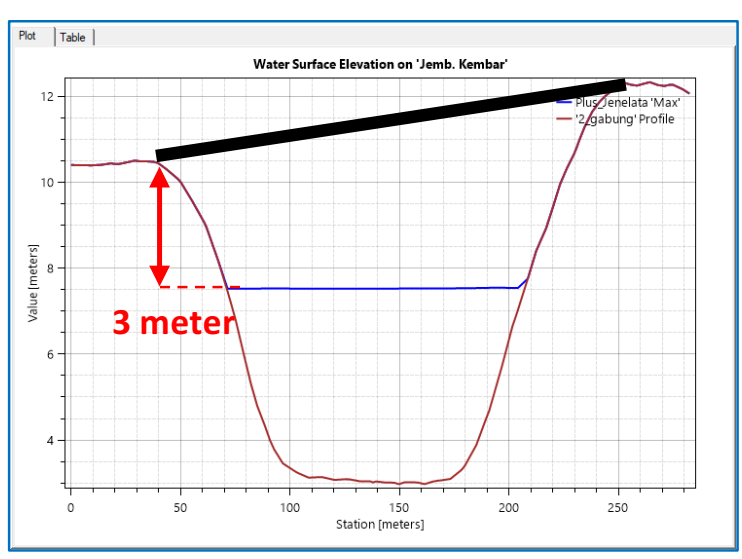

Gambar 11. Hasil model

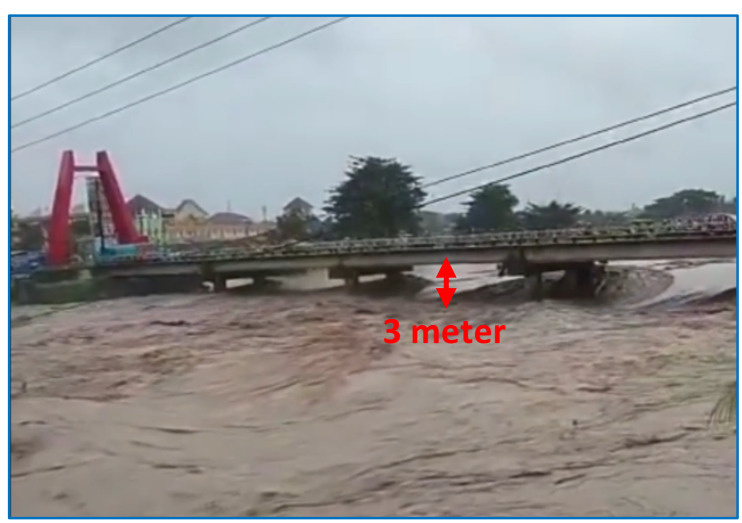

Gambar 12. Kejadian di lapangan

Setelah model tervalidasi dengan kejadian sebernarnya, langkah terakhir adalah meng-generate model dengan skenario keruntuhan total bendungan. Hasilnya bisa dilihat pada gambar berikut:

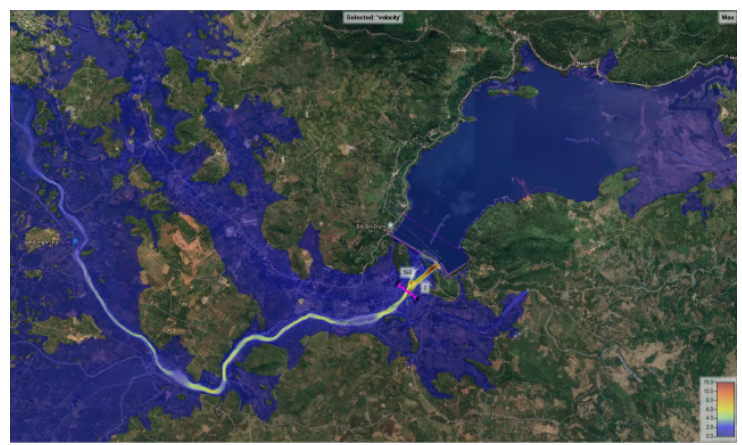

Gambar 13. Kondisi maksimum keruntuhan bendungan

dengan debit awal saat keruntuhan sebesar 24079.02 $\mathrm{m}^{3} /$ detik.

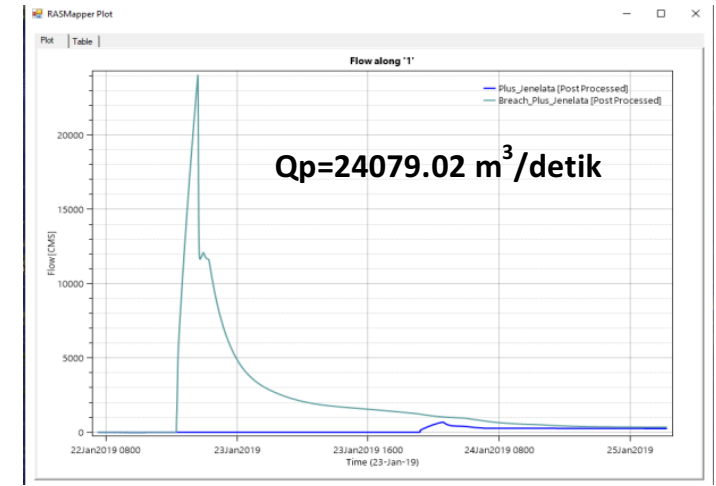

Gambar 14. Debit maksimum keruntuhan bendungan Bili-Bili

\section{KESIMPULAN DAN SARAN}

Simulasi aliran banjir akibat keruntuhan bendungan dapat dilakukan dengan program HECRAS 2D. Program HEC-RAS 2D sangat mudah dioperasikan dan dapat menampilkan nilai luas genangan banjir di hilir, ketinggian genangan, dan kecepatan aliran air. Berdasarkan hasil simulasi, dengan skenario runtuh total bendungan Bili-Bili, akan menyebabkan banjir besar hingga menenggelamkan sebagian besar kota Makassar.

\section{DAFTAR PUSTAKA}

BPSDM. 2017. Modul Operasi Waduk Modul 08. Pusat Pendidikan dan Pelatihan Sumber Daya Air dan Konstruksi, Bandung.

Brunner, G. 2014. Using HEC-RAS for Dam Break Studies. U.S. Army Corps of Engineers, Institute for Water Resources.

Goodell dan Warren C. 2006. Flood Inundation Mapping using HEC-RAS. Obras y Proyectos.

Rachmadan, C.R., Juwono, P.T. and Asmaranto, R., 2013. Analisa Keruntuhan Bendungan Alam Way Ela dengan Menggunakan Program Zhong Xing HY21. Universitas Bramawijaya. Malang.

Xiong, Y.F. 2011. A Dam Break Analysis Using HECRAS. Journal of Water Resource and Protection, p:370-379

http: / / psdasulsel.org/indeks.php/aset/116-profildaerah-irigasi-bili-bili-kabupaten-gowa. Diakses pada tanggal 19 November 2019 